\title{
Breastfeeding in the Australian Media
}

\author{
NICOLE BRIDGES* \\ University of Western Sydney
}

\begin{abstract}
Breastfeeding is a topic that frequently evokes extreme and passionate arguments - both for and against. The way a mother decides to nourish her baby can be one of the most antagonistic and emotive decisions she will ever make. A woman's decision to breastfeed is influenced by a number of factors: demographic, psychological, cultural and social, and it is often difficult to isolate which factors are most influential (Hector, King, \& Webb, 2005). One factor to be explored is the way the media represents and reports on breastfeeding issues, and the role the media can play in this decision-making process. This paper employs meta-analysis of existing literature and a limited content analysis of recent media coverage of high profile breastfeeding issues in Australia, to explore this issue.
\end{abstract}

\section{Introduction}

Human milk is the ideal food for human babies. It contains all the nutrients required for at least the first six months of a baby's life, and remains the most important part of his/her diet throughout the first year. This milk then supplies half or more of the required nutrients to his/her first birthday and up to one third to his/her second birthday and beyond (Australian Breastfeeding Association, 2006).

In 1990 the World Health Organization (WHO) and the United Nations International Children's Fund (UNICEF) stated that all infants should be fed exclusively on breast milk from birth, for the first four to six months of life and beyond (WHO/UNICEF, 1990). This, they claimed, would ensure optimal child and maternal health. By 2001, the recommended period for exclusive breastfeeding changed to six months. Despite this fact, many Australian babies are still weaned sooner than the WHO/UNICEF guidelines recommend. Australian mothers want to breastfeed - and initially do so. Breastfeeding in Australia begins well. The most recent National Health Survey, conducted in 2001, showed breastfeeding initiation of approximately 83\%. In 2001 it was found that by the age six months, around half (48\%) of all children were being breastfed (House of Representatives Standing Committee on Health and Ageing, 2007). Results from the 1995 and 2001 National Health Surveys indicate that the proportion of children receiving any breast milk declines steadily with age, with the number of fully breastfed babies at three months decreasing to approximately $57 \%$, and at six months, decreasing to approximately $18 \%$. Finally, at one year of age, there are only $23 \%$ of babies still receiving any breast milk at all as part of their normal diet, and $1 \%$ of children being breastfed by two years of age (House of Representatives Standing Committee on Health and Ageing, 2007). Data collected in NSW in 2004 indicated that $90 \%$ of newborn infants in NSW were put to the breast, or offered breast milk, at least once. However, only $77 \%$ of infants were receiving at least some breast milk regularly at the end of their first month. By six months of age, only $4.6 \%$ of babies in NSW were being exclusively breastfed (NSW Health, 2004). 
Currently, there is no mechanism is Australia for national monitoring of infant feeding rates (House of Representatives Standing Committee on Health and Ageing, 2007). However, in the 'Report on Breastfeeding in NSW 2004' make some key comparisons between breastfeeding data collected in the National Health Survey, 1995 (Donath \& Amir, 2000), and the NSW Child Health Survey, 2001 (NSW Health, 2002). A comparison of breastfeeding rates at hospital discharge indicates an increase in the rate in NSW between 1995 and 2001 from $78.4 \%$ to $86.5 \%$. However, rates of exclusive breastfeeding at six months were substantially lower in 2001 (4.6\%) than in 1995 (17.2\%) (NSW Health, 2004). These figures suggest that, although mothers start to breastfeed, they are weaning earlier and long-term breastfeeding rates have in fact declined.

\section{Literature Review}

The issues around the low rates of breastfeeding are complex. When a woman makes the decision to breastfeed, the attitudes of her partner and the community around her are factors that can influence this decision (House of Representatives Standing Committee on Health and Ageing, 2007). There is no argument that birth practices have a huge impact on breastfeeding success (Kroeger, 2004). To this end, Australia's increasing rate of birth interventions and caesareans (Benson, 2010) is reflected in the fact that many women struggle to establish breastfeeding. Interactions with health professionals and provision of breastfeeding support also affect the duration of breastfeeding, as does having to return to work (House of Representatives Standing Committee on Health and Ageing, 2007).

The role of the mass media in this decision-making process is important, particularly its relationship with public health issues and promotion of them. This is evidenced in the column space allocated to health and medical issues in the print media (Chapman \& Lupton, 1994). The media are skilled at reporting on the public health agenda and stimulating public opinion about what is important and worthy of action (Westwood \& Westwood, 1999). Mass media can thus influence health consciousness, knowledge, and attitudes that can cause behavioural and social change (Hotham, 1995). It therefore follows that the content of the mass media exerts influence over the decision of whether or not to breastfeed. While journalists, breastfeeding advocates, and others shaping media content have periodically promoted breastfeeding, especially in the 1920s and the late 1970s, many have suggested that the mass media has often discouraged breastfeeding, by diffusing information about artificial infant milk, reinforcing many factors that discouraged breastfeeding, and promoting modernity and social status (Foss \& Southwell, 2006). However, news organisations have also been accused of perpetuating the myths that breastfeeding is dangerous. Cases of breastfeeding failures, such as infant starvation or the transmission of the mother's illness through her breast milk, frequently received publicity. Although the risks of feeding with artificial infant milk far outweigh the risks of breastfeeding, sensationalistic journalism such as these examples may have convinced mothers that artificial infant milk was less risky, thus influencing them to wean their baby (Wolf, 2001).

Henderson, Kitzinger \& Green (2000) used content analysis to investigate how infant feeding was represented by the British media. They measured visual and verbal references to breastfeeding or feeding with artificial infant milk in newspapers and television programs. Within the television sample, they identified 235 visual or verbal references to infant feeding. In the press sample, there were 38 references to infant feeding in 37 different newspaper editions. Their study reported that breastfeeding and feeding with artificial infant milk are portrayed very differently by the mass media. Feeding with artificial infant milk was shown more often than breastfeeding and was represented as being less problematic. Artificial infant 
milk was associated with "ordinary" families, whereas breastfeeding was associated with middle-class women or celebrities. Depiction of the health risks of artificial infant milk were also missing from the coverage (Henderson et al., 2000). These limited portrayals of breastfeeding in the media may help to perpetuate a lack of acceptance of breastfeeding in public. They may also result in sustaining notions that breastfeeding is difficult, likely to fail, or that it is an option only for certain types of women (that is, middle-class or 'celebrities'). It seems that in this instance, artificial infant milk is normalised and represented as the obvious choice (Henderson, et al., 2000).

Bandura (1986) states that the mass media can also influence behaviour through direct means (e.g. an article providing information about infant feeding) and indirect modelling of behaviours and their consequences (e.g. portraying a female character in a soap opera having breastfeeding difficulties). Both of these methods can affect the audience's beliefs about the expected outcomes of specific practices and the value they attach to those outcomes (Bandura, 1986). Social Cognitive Theory states that behaviour modelling and vicarious experience can affect behaviour by influencing 'self-efficacy' or attitudes and commitment toward behaviour (Bandura, 1986). The concept of self-efficacy - in other words, whether an individual thinks he/she can do something - is very important to the breastfeeding experience. It is therefore insufficient to simply tell a mother that breastfeeding is a really good idea. In addition to believing it is a good idea, she must also think that she is the type of person who can do it. And if she does experience problems, she needs to think that she is the type of person who, with help, will be able to sort them out (Thomas, 2006).

Sheeshka, Woolcott and MacKinnon (1993) found the media to be an important influence on intentions to adopt healthy eating patterns and their study suggests that behaviour modelling in the media may increase self-efficacy for behavioural performance. In the case of infant feeding, if a mother is exposed to indirect messages such as women breastfeeding with ease on their favourite soap opera, then she may feel more confident in her own ability to breastfeed in similar situations and thus become more committed to breastfeeding. Similar research has also examined behaviour modelling whilst examining preschoolers' attitudes, expectations, and perceptions of tobacco and alcohol use (Dalton, et al., 2005b). During a structured observational study, children used props and dolls to act out a social evening for adults. As part of the role play, each child selected items from a miniature grocery store stocked with 73 different products, including beer, wine, and cigarettes, for an evening with friends. The main outcome measure was whether or not a child purchased cigarettes or alcohol at the store.

Interestingly, $28.3 \%$ of the children purchased cigarettes and $61.7 \%$ purchased alcohol. Children were more likely to buy cigarettes if their parents smoked. Similarly, participants were more likely to buy beer or wine if their parents drank alcohol at least monthly, or if they viewed PG or R rated movies. Children's play behaviour suggests that they are highly attentive to the use and enjoyment of alcohol and tobacco and have well-established expectations about how cigarettes and alcohol fit into social settings (Dalton, et al., 2005a). If adult behaviour, especially parental behaviour, influences preschool children to view smoking and drinking as appropriate or normative in social situations, then it can be posited that childhood perception of adult behaviours may also elate to other behaviours adopted later in life, including infant feeding and care.

The view that "mass media may affect behaviour by both providing models of behaviour and presenting information about the consequences of behaviour" (Potter et al., 2000, p. 202) indicates that most women make infant feeding decisions before conception, or while 
pregnant, and that the print media influence attitudes and infant feeding decisions by promoting certain products and practices. This promotion can occur deliberately, by way of paid advertising, or unintentionally, through the descriptions and portrayals in editorials, pictures, and articles. The latter provide a revealing insight into society's views of nutrition and parenting, and the relationship between media messages, societal values, and health behaviour.

Over the years, there have been many analyses of nutrition messages in the media; however few have focused on infant feeding. Young (1990) examined infant feeding as part of a content analysis study of infant development messages contained in popular parenting magazines and manuals. It is interesting to note the changes in attitudes to infant feeding methods over time. In the 1950s breastfeeding was depicted as the preferred infant feeding method, whereas the 1960s and 1970s saw mothers being told that breast milk and artificial infant milk were equal. In the early 1980s, breastfeeding was once again emphasised. It was found that changes in health messages over time mirror both scientific evidence and people's values (Young, 1990).

Henderson (1999) used discourse analysis to examine representations of breastfeeding in articles published in the Australian press and popular magazines over a six-month period. Discourse analysis focuses on sociocultural and political contexts in which communication occurs (Lupton, 1993). Henderson (1999) firstly made a survey of popular magazines in Australia for accuracy of information about drugs and environmental influences during pregnancy. Statements were assessed as accurate, misleading or inaccurate, and as provoking anxiety or giving a false sense of security. The survey concluded that the media was an influential source of information about health and lifestyle issues (Hotham, 1995).

Robinson and Thomson (1989) revealed that factors associated with the decision to breastfeed, included knowledge about breastfeeding, attitudes toward breastfeeding, role models, and embarrassment. A subsequent study concluded that the sources of knowledge that parents used included newspapers, magazines, television, and books (Robinson \& Thomson 1989).

Henderson (1999) concluded that the print media in Australia was suggesting that breastfeeding is best and natural yet fraught with problems. Mixed messages and meanings were being expressed in many articles. Some were obvious, others were powerful and persuasive, others yet were subtle but sure. Relationships between knowledge, power, and practices of breastfeeding illustrate an overall polemic view that may influence the reader not to breastfeed, even though breastfeeding is the optimal way to feed human babies.

Foss and Southwell (2006) examined infant feeding advertisements in 87 issues of Parents' Magazine in the U.S., between 1971 and 1999. Using content analysis results to predict subsequent changes in levels of breastfeeding among U.S. women, they discovered that when the frequency of artificial infant milk advertisements increased, the percentage change in breastfeeding rates reported the next year generally tended to decrease. Their results emphasise the need to acknowledge the potential role of popular media content in understanding breastfeeding patterns and public health trends.

Theories recognising the powerful influence of the media have been around for many years. The form and content of media are continuously evolving as the amount of knowledge doubles every two years (McQuail, 2005). Whatever changes may occur, the significance of media in our society permeates politics, culture, social life, and economics. Our daily lives 
are strongly patterned by the routines of media use, and affected by its contents through the way we spend our leisure. Our conversations are given their topics and models of behaviour, for all possible outcomes (McQuail, 2005).

A significant mass media theory is based upon the research of Blumler and Katz (1974). Even in the early days of empirical mass communication research, an academic interest in the short-term effects of media consumption was matched by an interest in the gratifications that the media provide their audiences (Blumler \& Katz, 1974). Preliminary research studies carried out in the 1940s came up with a list of functions served by the contents of the media, or the actual media itself "to match one's wits against others, to provide a framework for one's day, to prepare oneself culturally for the demands of upward mobility, to be reassured about the dignity and usefulness of one's role, or to get information or advice for daily living” (Blumler \& Katz, 1974, p. 20). It is this final 'use' for the media that is particularly relevant when exploring the relationship between infant feeding decisions and the media. It appears that there has been a recognised influence of media for quite some time - indeed, consumers do use the mass media as a reliable source of information for all aspects of their daily lives. The research of Blumler and Katz was the beginning of what is now known as the 'uses and gratifications' approach. This approach is an attempt to explain the way individuals use communications, among other resources in their environment, to satisfy their needs and to achieve their goals (Blumler \& Katz, 1974).

Blumler and Katz (1974) aimed to establish a theoretical framework within which to place the many findings about audience motivations. McQuail et al. (1972) proposed a scheme of 'media-person interactions' which encompasses the most relevant media satisfactions. This scheme demonstrated that the media is used not only to entertain and provide other forms of self-actualisation, it is also perceived as a means to obtain information. Attitudes, social norms and cultural opinion about infant feeding are potentially shaped by the media via books, magazines, television, videos, and the internet. For example, a culture that focuses on body image and which sees breasts as sexual organs (Dykes \& Griffiths, 1998) can reduce a woman's willingness to breastfeed in public (Hoddinott \& Pill, 1999). One of the key influences on a woman's choice to breastfeed is the perception that it is unacceptable and inappropriate to breastfeed in public (Bartlett, 2002). This belief harks back to negative Victorian notions of patriarchy's claim to the city by separating it "into public/male versus private/female” (Bartlett, 2002, pp. 114-115). A focus group study found that male university students believed that breastfeeding in public is the domain of "left-wing radicals, greenies, and feminists” (Bartlett, 2002, p. 115). These findings assert Mepham's (1991, p. 28) belief that "the principal reason for the decline in breastfeeding is a widespread lack of appreciation of its real nature and importance in human development”.

\section{Recent research}

The media rarely show breasts in their natural state - feeding babies. When they do, they rarely present positive information on breastfeeding, even though this is the biologically normal way to feed a human baby. They are also usually criticised by consumers who take the moral high ground. In fact, breastfeeding in public is an issue that has attracted a large amount of media scrutiny in the past several years in Australia.

Kirstie Marshall, a member of the Victorian State Parliament, caused a parliamentary sensation on 26 February 2003 when she was ejected from the chamber of the Legislative Assembly for breastfeeding her 12-day-old daughter, Charlotte Louise, before the first question was even asked. The new backbencher was forced to remove the "stranger" she had 
brought on to the floor of the Assembly. Under parliamentary rules only MPs and certain parliamentary staff are permitted on the floor during sitting times. Marshall said she was not aware of the rule and had simply been running late that day and had not been able to reach her mother who would take care of the newborn. Her decision to breastfeed in Parliament generated significant response.

Critics argued that there is a time and place for breastfeeding and parliamentary question time is not it. They also claimed that other working mothers cannot work and feed their baby at the same time and suggested that Marshall find adequate childcare if she wanted to continue her job. The workplace was thus identified as a professional environment and no place for children (Gray \& Dubecki, 2003). However, there were many supporters. Women's groups were particularly outraged at the treatment of Ms Marshall, saying the Victorian Parliament was stuck in the last century (Gray \& Dubecki, 2003)

A search of the major Australian newspapers using the Factiva database revealed a total of 12 articles were printed in Australia the following day, which included the terms "breastfeeding" and "Kirstie Marshall". An additional 83 articles including these terms were published in the following weeks, months and years, up to and including $25^{\text {th }}$ June, 2009. Who would have thought that one basic, biological act could create news content spanning more than a sixyear period?

In addition, the Daily Telegraph in Sydney promoted an online poll which asked the question "Victorian MP Kirstie Marshall was ejected from parliament for breastfeeding her baby. Can this exclusion be defended?" Not surprisingly, the results were "Yes" 62\% and "No" 38\%. Many of the media headlines at the time were sensationalistic with negative connotations such as: "Why the floor of Parliament is no place for infants," "Fed up with a feeding frenzy," "Breastfeeding debate bubbles on," and "Charlotte makes a meal of question time". This type of sensationalism does no favours for breastfeeding mothers. In fact, it only serves to further polarise public opinion on the issue, and turn a natural and normal act into a freak show.

On 17 September 2003, The Panel, a chat show on Australian television, showed television personality Kate Langbroek, breastfeeding her son Louis live on air. It had not been a premeditated plan, but rather something that happened by chance. Ms Langbroek was visiting the show as a special guest six weeks after giving birth to Louis. Whilst the show was airing, her son was crying for a feed, so his carer brought him to her on set whilst the show was live to air.

A search of Factiva brings up a total of 14 articles were printed in Australia in the following weeks, months and years, up to and including 2 November, 2008 which included the terms "breastfeeding" and "Kate Langbroek". Ms Langbroek was labeled everything from "television's reigning queen of breastfeeding" (Schembri, 2005) to "the poster girl for breastfeeding mothers" (Hargreaves, 2007) and the less flattering "very unfunny comic Kate Langbroek who breastfed her baby on TVs The Panel" (Quigley, 2007). Fortunately, the Daily Telegraph spared us the online poll this time!

A Network Ten spokeswoman said the station had received about 10 calls, all of them supportive of Langbroek (Dasey, 2003). However, the court of public opinion was soon in session with Sydney and Melbourne radio talk show hosts criticising the entertainer and igniting a public debate. Radio station 2UE afternoon presenter Steve Price said Langbroek 
should not have brought her baby to work and breastfed on air (Dasey, 2003). Ironically, later on in the same episode of The Panel, there was a short video clip shown of a half naked woman cleaning a car with her bikini clad breasts the centre of attention. This did not attract a single complaint. What hope do women have, when the normal way for breasts to be portrayed on television is in a sexually explicit manner and feeding a baby is the event that attracts all of the negative attention?

These case studies support the research of Henderson et al. (2000) by demonstrating that the media sustain the notion that breastfeeding is an option only for certain types of women such as celebrities like Marshall and Langbroek. Likewise, we are also reminded of the work of Dykes \& Griffiths (1998) who purport that when breasts are portrayed as sexual organs, a woman's willingness to breastfeed in public can be reduced.

\section{Conclusion}

On reflection, the media play a significant role regarding the way society views breastfeeding, by the way it represents this natural act. Indeed, it would be too simplistic to assume that the media is the major cause of the empirical shift away from breastfeeding. Rather, as this paper has demonstrated, it acts as a filter, caught between family (the public/readers) and industry (advertisers).

\section{References}

Australian Breastfeeding Association (2006). Breastfeeding ... naturally. Melbourne: Australian Breastfeeding Association.

Bandura, A. (1986). Social foundations of thought and action: a social cognitive theory. New Jersey: Prentice-Hall.

Bartlett, A. (2002). Scandalous practices and political performances: Breastfeeding in the city. Journal of Media \& Cultural Studies, 16(1), 111-121.

Benson, K. (2010, 8 January). Rise in induced births worries doctors. Sydney Morning Herald, p. 1.

Blumler, J. G., \& Katz, E. (1974). Uses of mass communications: Current perspectives on gratifications research. Beverley Hills: Sage Publications.

Chapman, S., \& Lupton, D. (1994). The fight for public health. Principles \& practice of media advocacy. London: BMJ Publishing Group.

Dalton, M., Bernhardt, A., Gibson, J., Sargent, J., Beach, M., Adachi-Mejia, A., et al. (2005a). Use of Cigarettes and Alcohol by Preschoolers While Role-playing as Adults. Archives of Pediatrics and Adolescent Medicine, 159(1), 854-859.

Dasey, D. (2003, 19 September). Sure fire way to milk a reaction. Sydney Morning Herald. Retrieved January 12, 2010 from http://www.smh.com.au/articles/2003/09/18/1063625153238.html

Donath, S., \& Amir, L. (2000). Rates of breastfeeding in Australia by State and socio-economic status: Evidence from the 1995 National Health Survey. Journal of Pediatrics and Child Health, 36, 164-168.

Dykes, F., \& Griffiths, H. (1998). Societal influences upon initiation and continuation of breastfeeding. British Journal of Midwifery, 6(2), 76-80.

Foss, K., \& Southwell, B. (2006). Infant feeding and the media: the relationship between Parents' Magazine content and breastfeeding, 1972-2000. International Breastfeeding Journal, 1(10), 1-9.

Gray, D., \& Dubecki, L. (2003, 27 February). Charlotte makes a meal of question time. The Age. Retrieved November 2, 2009 from http://www.theage.com.au/articles/2003/02/26/1046064105574.html

Hargreaves, W. (2007, 5 July). Age of the baby boom. The Age. Retreived January 12, 2010 from http://www.theage.com.au/news/tv--radio/art-of-the-baby-boom/2007/07/03/1183351217626.html Hector, D., King, L., \& Webb, K. (2005). Factors affecting Breastfeeding Practices - applying a conceptual framework. NSW Public Health Bulletin, 16(3-4), 52-55. 
Henderson, A. (1999). Mixed messages about the meanings of breastfeeding representations in the Australian press and popular magazines. Midwifery, 15(1), 24-31.

Henderson, L., Kitzinger, J., \& Green, J. (2000). Representing infant feeding: content analysis of British media portrayals of bottle feeding and breastfeeding. BMJ, 321(1), 196-198.

Hoddinott, P., \& Pill, R. (1999). Nobody actually tells you: a study of infant feeding. British Journal of Midwifery, 7(9), 558-565.

Hotham, N. (1995). Information on drugs and environmental influences in pregnancy in popular magazines: a critical review. The Medical Journal of Australia, 162, 417-419.

House of Representatives Standing Committee on Health and Ageing (2007). The Best Start: Report on the inquiry into the health benefits of breastfeeding. Canberra: The Parliament of the Commonwealth of Australia.

Kroeger, M. (2004). Impact of birthing practices on breastfeeding. Sudbury: Jones and Bartlett Publishers.

Lupton, D. (1993). Discourse analysis: A new methodology for understanding the ideologies of health and illness. Australian Journal of Public Health, 16(2), 145-150.

McQuail, D. (2005). McQuail's Mass Comunication Theory (5th ed.). Oxford: The Alden Press.

McQuail, D., Blumler, J., \& Brown, J. (1972). Sociology of Mass Communication. Harmondsworth: Penguin.

Mepham, B. (1991). Cognitive impediments to breast-feeding: A communications challenge. Media Information Australia, 61, 28-35.

NSW Health (2002). New South Wales Child Health Survey 2001. Sydney: NSW Department of Health.

NSW Health (2004). Report on breastfeeding in NSW 2004. Sydney: NSW Department of Health

Potter, B., Sheeshka, J., \& Valaitis, R. (2000). Content Analysis of Infant Feeding Messages in a Canadian Women's Magazine, 1945 to 1995. Journal of Nutrition Information, 32(4), 196-203.

Quigley, A. (2007, 2 October). Forced to live, work and wean in a mummy state. The Daily Telegraph, p. 1.

Schembri, J. (2005, 22 December). Critic's View. The Age, p. 1.

Thomas, P. (2006). Suck on this. Retrieved September 13, 2007, from http://www.theecologist.org/archive_detail.asp?content_id=586

Westwood, B., \& Westwood, G. (1999). Assessment of newspaper reporting of public health and the medical model: A methodological study. Health Promotion International, 14(1), 53-64.

WHO/UNICEF (1990). Breastfeeding in the 1990s: Implications for a global strategy. Geneva: World Health Organisation.

Wolf, J. (2001). Don't kill your baby: Public health and the decline of breastfeeding in the nineteenth and twentieth centuries. Columbus: The Ohio State University Press.

Young, K. (1990). American conceptions of infant development from 1955 to 1984: What the experts are telling parents. Child Development, 61, 17-28.

Nicole Bridges is an Associate Lecturer in public relations and advertising at the University of Western Sydney. She holds a Bachelor of Communication (Hons) and has recently embarked on a $\mathrm{PhD}$, researching the relationship between breastfeeding success and involvement in online social networking. Nicole has also been a volunteer breastfeeding counsellor with the Australian Breastfeeding Association for 8 years. 